\section{Bacteriemia por Serratia rubidaea con fenotipo atípico de resistencia a quinolonas}

\author{
Delicia Gentille, Mar Pérez y María José Centelles
}

\section{Bacteremia by a Serratia rubidaea with an atypical quinolones resistance phenotype}

Serratia spp. causes the $2 \%$ of nosocomial infections. Serratia marcescens is the pathogenic species for excellence as it causes more than $90 \%$ of cases, however, there are very few reported cases of clinical infection caused by other minority species, among which is $S$. rubidaea. We present a case of nosocomial bacteremia by $S$. rubidaea, probably related to a peripheral catheter, in a healthy teenager who consulted to the emergency room after suffering a fit while practicing strenuous sport.

Key words: Serratia spp, Serratia rubidaea, nosocomial infection, antibiotic resistance.

Palabras clave: Serratia spp, Serratia rubidaea, infección nosocomial; resistencia antimicrobiana.

\section{Introducción}

E 1 género Serratia incluye bacterias oportunistas de la familia Enterobacteriaceae que no forman parte de la microbiota intestinal humana habitual. Su hábitat es la naturaleza ${ }^{1}$. Serratia spp. es causante de $2 \%$ de las infecciones nosocomiales, siendo Serratia marcescens la responsable de más de $90 \%$ de los casos. Existen muy pocos reportes de infecciones causadas por otras especies ${ }^{2}$.

\section{Caso clínico}

Adolescente de 15 años, previamente sano, ingresó a Urgencia tras sufrir un síncope mientras practicaba un ejercicio extenuante, en un campo de fútbol, sometido a alta temperatura ambiental. Al examen físico presentaba febrícula de $37,3{ }^{\circ} \mathrm{C}$, P. arterial de $97 / 54 \mathrm{mmHg}$; sudoración profusa y taquicardia sinusal a $179 \mathrm{lpm}$, siendo la auscultación cardio-respiratoria normal. Luego de la administración de fluidos intravenosos logró estabilidad hemodinámica; sin embargo, presentó fiebre de $37,8^{\circ} \mathrm{C}$, alteración progresiva de la función hepática y renal, leucocitosis y elevación de enzimas musculares. Fue internado con diagnóstico de síncope por calor, taquicardia sinusal, insuficiencia renal aguda, citolisis hepática y rabdomiolisis secundarias. $\mathrm{Al} 4^{\circ}$ día de hospitalización presentó fiebre, por lo que al día siguiente se tomaron dos parejas de hemocultivos para aerobios y anaerobios. A pesar del uso de antitérmicos, el paciente persistió con fiebre, hasta $39,2^{\circ} \mathrm{C}$; vómitos y escalofríos. Como foco probable se detectó la presencia de una flebitis secundaria a una vía venosa periférica en el antebrazo derecho, canalizada a su ingreso. Por este motivo, el día 7 se retiró el catéter, sin enviarlo a cultivo.

Hospital de Tortosa Verge de la Cinta. IISPV. Tarragona, España.

Servicio de Cardiología (DG). Laboratorio Clínico ICS-Terres de l'Ebre (MP, MJC)

Recibido: 4 de enero de 2014 / Aceptado: 24 de marzo de 2014

\section{Correspondencia a:}

Delicia Gentille

dgentille.ebre.ics@gencat.cat.
El paciente evolucionó con febrículas hasta el día 9 del ingreso en que llegó a estar afebril. El día 8 (tras 3 días de incubación) se detectó crecimiento bacteriano en los cuatro frascos de hemocultivos. En los sub-cultivos en agar McConkey, sangre, chocolate y Schaedler creció un bacilo gramnegativo, oxidasa negativa y catalasa positiva. Fue identificado como Serratia rubidaea mediante un panel 95W (Soria Melguizo S.A. Madrid. España), galería API 20E (bioMérieux. Marcy L'Etoile. Francia) y espectrometría de masas MALDI-TOF Microflex (Brucker. Berlín. Alemania). El antibiograma por microdilución en caldo en el panel 95W mostró que el microorganismo era susceptible a amoxicilina, amoxicilina/ácido clavulánico, piperacilina/ tazobactam, ceftazidima, cefotaxima, cefepima, imipenem, meropenem, ertapenem, gentamicina, tobramicina, y amikacina y resistente a cefazolina, cefoxitina y cefuroxima. El aislado tenía una sensibilidad disminuida a ciprofloxacina (CIM de $0,4 \mu \mathrm{g} / \mathrm{ml}$ por epsilometría) pero era susceptible a ácido nalídíxico (CIM $\leq 16 \mu \mathrm{g} / \mathrm{ml}$ ). Se investigó por RPC la presencia de determinantes de resistencia transferible a quinolonas (DRTQ) $q n r A, q n r B$, $q n r S, q n r C, q n r D$, qepA y aac(6')-Ib-cr, los que resultaron todos negativos.

A la vista de los resultados microbiológicos y ante la lenta mejoría de la flebitis, el día 10 del ingreso se inició imipenem. La resolución completa de la flebitis se logró al $7^{\circ}$ día de tratamiento y el paciente fue dado de alta tras completar 10 días de terapia antimicrobiana.

\section{Discusión}

Serratia rubidaea es una enterobacteria cuyo hábitat no es bien conocido; sin embargo, se ha encontrado en la naturaleza: en frutas, vegetales y en el coco; no así en el agua, insectos, pequeños mamíferos u otros animales ${ }^{3}$. Su aislamiento como agente causal de infección en humanos es excepcional, habiéndose comunicado pocos casos de infección clínica.

Es un patógeno oportunista, generalmente nosocomial, que afecta a pacientes debilitados o inmunocomprometidos ${ }^{4}$, sometidos a tratamiento antimicrobiano de amplio espectro, cirugías extensas, instrumentalización de la vía urinaria u otros procedimientos invasores. Se ha descrito como agente causal de infecciones del tracto respiratorio, urinario, de úlceras o heridas. Se ha aislado en piel, excrementos, bilis y sangre ${ }^{1-8}$. Su identificación es relativamente sencilla usando los métodos de identificación comerciales.

Susceptibilidad antimicrobiana: a pesar de que produce en forma natural una $\beta$-lactamasa cromosomal de tipo AmpC no inducible (a diferencia del resto de las especies del género), responsable de la resistencia a cefalosporinas de $1^{\mathrm{a}}$ y $2^{\mathrm{a}}$ generación y cefamicinas, muchas de las cepas, como la que describimos, se mantienen sensibles a las amino y ureidopenicilinas ${ }^{9}$. En cuanto al fenotipo particular de resistencia a las quinolonas, característico de los aislados portadores de DRTQ, no pudimos identificar ninguno de los determinantes de codificación plasmidial habituales. Es posible, por lo tanto, que fuese conferido por un determinante de resistencia a fluoroquinolonas de codificación cromosómica como Smaqnr, identificado previamente en $S$. marcescens y que codifica una proteína de 214 aminoácidos con $80 \%$ de homología con QnrB1 ${ }^{10}$.

Consideramos que el caso descrito resulta de interés por tratarse de una bacteriemia de origen nosocomial por Serratia rubidaea, especie infrecuente, con un fenotipo atípico de resistencia a quinolonas, en un adolescente previamente sano. Su origen probable fue una flebitis asociada a un catéter venoso periférico. La infección pudo producirse durante la inserción de la vía, por una deficiente asepsia de una piel contaminada en el campo de fútbol. La cronología de los acontecimientos (existencia de un procedimiento invasor de urgencia, el inicio de la fiebre, la presencia de la flebitis, la existencia de cuatro hemocultivos positivos para este microorganismo y el hecho de que el paciente se hiciera afebril a las $48 \mathrm{~h}$ de retirar la vía periférica) hacen posible esta asociación, a pesar que no se dispuso de confirmación microbiológica al no haberse realizado cultivo del catéter. 
Agradecimientos. Los autores agradecen la colaboración del Dr. Frederic Gómez, de Microbiología Clínica del Hospital Joan XXIII de Tarragona, en la confirmación de la identificación del microorganismo por MALDI-TOF.

\section{Referencias bibliográficas}

1.- Samonis G, Vouloumanou E K, Christofaki M, Dimopoulou D, Maraki S, Triantafyllou E, et al. Serratia infections in a general hospital: characteristics and outcomes. Eur J Clin Microbiol Infect Dis 2011; 30: 653-60.

2.- Sekhsokh Y, Arsalane L, El Ouenass M, Doublali T, Bajjou T, Lahlou Amine I. Serratia rubidaea bacteremia. Med Mal Infect 2007; 37 : 287-9.

3.- Ursua P R, Unzaga M J, Melero P, Iturburu I, Ezpeleta C, Cisterna R. Serratia rubidaea as an invasive pathogen. J Clin Microbiol 1996; 34: 216-7.

4.- Okada T, Yokota E, Matsumoto I. Community acquired sepsis by Serratia rubidaea. Kansenshogaku Zasshi 2002; 76: 109-12.
5.- Parment P A, Ursing J, Palmer B. Serratia rubidaea isolated from a silastic foam dressing. Infection 1984; 12: 268-9.

6.- Saito H, Elting L, Bodey G P, Berkey P. Serratia bacteremia: review of 118 cases. Rev Infect Dis 1989; 11: 912-20.

7.- Litterio M L, Arazi S, Hernández C, Lopardo H. Isolation of Serratia rubidaea from a mixed infection after a horse bite. Rev Argent Microbiol 2012; 44: 272-4.

8.- Vijayakrishnan R, Kouser J, Abraham G. Serratia rubidaea as a rare cause of gram-negative bacteremia. Infect Dis Clin Pract 2010; 18: 336-7.

9.- Stock I, Burak S, Sherwood K J, Grüger T, Wiedemann B. Natural antimicrobial susceptibilities of strains of 'unusual' Serratia species: S. ficaria, S. fonticola, S. odorifera, S. plymuthica and S. rubidaea. J Antimicrob Chemother 2003; 51: 865-85.

10.- Velasco C, Rodríguez-Martínez J M, Briales A, Díaz de Alba P, Calvo J, Pascual A. Smaqnr, a new chromosome-encoded quinolone resistance determinant in Serratia marcescens. J Antimicrob Chemother 2010; 65: $239-42$. 